\title{
A rare and potentially fatal complication of amoebiasis: acute fulminant necrotizing amoebic colitis
}

\author{
S Raviraj', M Sivashankar', A Ekanayake ${ }^{1}$ \\ Ceylon Medical Journal 2017; 62: 63-64 \\ DOI: http://doi.org/10.4038/cmj.v62i1.8436
}

A 65-year old male was admitted to surgical casualty with symptoms and signs of acute intestinal obstruction. He has been a toddy drinker for more than twenty years. Distended small and large bowel shadows were noted on the supine abdominal x-ray and inflammatory markers were elevated in blood. He underwent emergency laparotomy; descending colon and proximal part of sigmoid colon were found to be necrotic, with multiple perforations and a loculated abscess in the left paracolic gutter. The necrotic bowel loops were resected and the viable distal sigmoid colon was closed and an end colostomy was created.

Macroscopically, specimen consisted of pieces of large bowel, measuring up to $15 \mathrm{~cm}$ in length and $6 \mathrm{~cm}$ in diameter, with patchy areas of full-thickness soft, white necrosis of the wall, ulcers with necrotic material adherent to their bases and large perforations (Figure 1). The ulcers were typically flask shaped, with a narrow neck and broad, undermined base. Microscopically, the affected bowel wall showed ischaemic necrosis with a mixed inflammatory cell infiltrate and small clusters of dispersed amoebic trophozoites (Figure 2 and 3). Periodic Acid Schiff staining was positive. The necrosis was transmural in the areas of perforation, and amoebic trophozoites were also seen within the lumen of blood vessels.

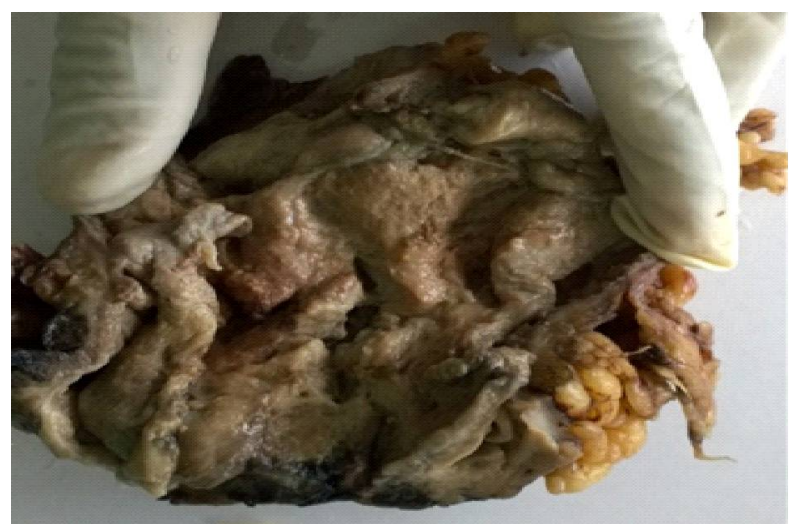

Figure 1. A segment of colon showing mucosal ulcers with slough on the surface.

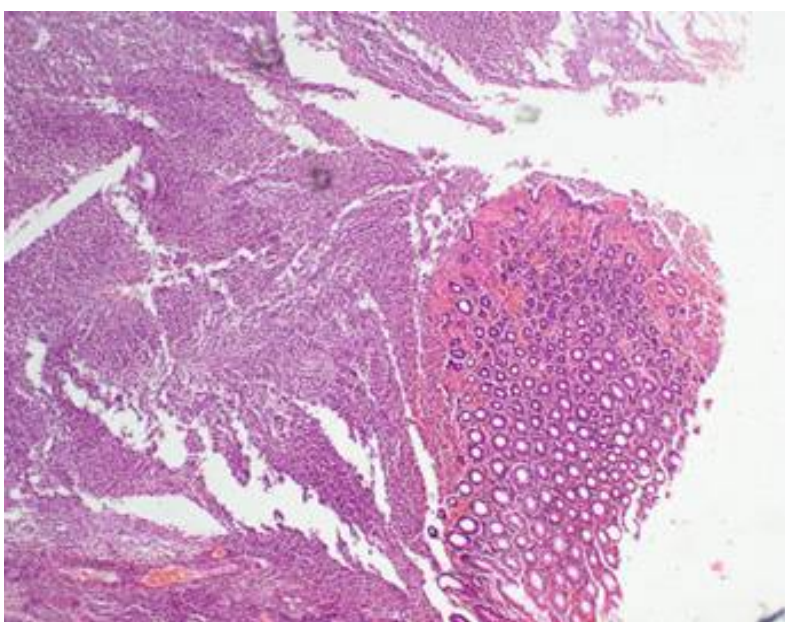

Figure 2. H \& E (4x10) Part of a flask shaped ulcer with undermined edges.

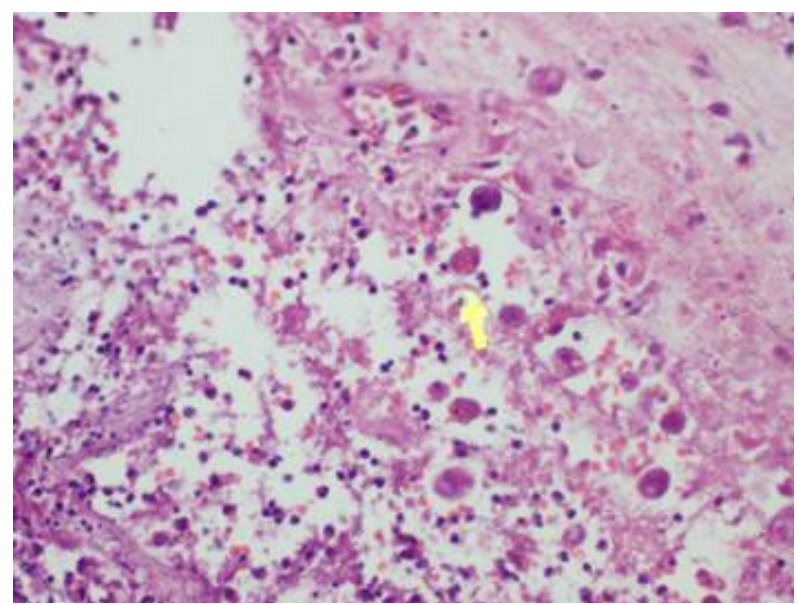

Figure 3. H \& E (40x10) amoebic trophozoites with ingested red blood cells (arrow) in a necrotic background.

${ }^{1}$ Teaching Hospital Jaffna, Sri Lanka.

Correspondence: SR, e-mail:<dr.s.raviraj@gmail.com>. Received 14 May 2016 and revised version accepted 25 October 2016.

This is an open-access article distributed under the terms of the Creative Commons Attribution License, which permits unrestricted use, distribution, and reproduction in any medium, provided the original author and source are credited. 
Entamoeba histolytica affects the large intestine and liver in humans. Infection occurs due to ingestion of cysts of the parasites from water or food which is contaminated with faeces. It may involve any part of the large bowel but it has a predilection for the caecum and ascending colon. The vast majority (90\%) of humans harboring this organism are asymptomatic carriers; only $6-11 \%$ of patients have a symptomatic infection. The most virulent host response to amoebic infection is fulminant necrotizing colitis and perforation, as in this reported case.

Conventional microscopic examination of stool has a low sensitivity $(25 \%)[2,4]$. Antigen detection in the patient's stool and serum is the most sensitive and specific investigation $[2,5]$. CT is the imaging of choice for diagnosis and assessment for complications of amoebic colitis [4]. This case highlights the fact that extreme forms of amoebiasis exist even now. For good outcome, clinicians should be aware of the importance of early detection, resuscitation and anti-amoebic treatment, along with urgent extensive resection of necrotic bowel loops.

\section{References}

1. Kumar V, Abbans, AK, Fanto N, Robbins and Cotran. Pathologic Basis of Disease. 7th Edition: 2006; 839-40.

2. Gupta SS, Singh O, Shikla S, Raj MK. Acute fulminant necrotizing amoebic colitis: a rare and fatal complication of amoebiasis: a case report. Cases J 2009; 2: 6557.

3. Shilpa N, Shashikala P, Manjula A, Swamy V. Acute Fulminant Amebic Colitis - A case report. J Pub Health Med Res 2013; 1: 104-5.

4. Kung shin Y, lai PC, Shin HW, Tai YC, et al. CT fingings of fulminant Amoebic colitis: a case report. Chin J Radiol 2008: 33: $205-10$.

5. Ishida $\mathrm{H}$, Inokuma $\mathrm{S}$, Murata $\mathrm{N}$, et al. Fulminant amoebic colitis with perforation successfully treated by staged surgery: a case report. J Gastroenterol 2003; 38: 92-6. 